\title{
Pseudomonas fluorescens/putida Group
}

National Cancer Institute

\section{Source}

National Cancer Institute. Pseudomonas fluorescens/putida Group. NCI Thesaurus. Code C86962.

A non-taxonomic grouping of bacteria assigned to the Pseudomonas genus that includes the species P. fluorescens and P. putida. 